\title{
A Laser Reduced Graphene Oxide Grid Electrode for the Voltammetric Determination of Carbaryl
}

\author{
Muhammad Saqib ${ }^{1,2}{ }^{\oplus}$, Elena V. Dorozhko ${ }^{1}$, Jiri Barek ${ }^{1,2}, * \mathbb{D}$, Vlastimil Vyskocil ${ }^{2}$, Elena I. Korotkova ${ }^{1}$ and \\ Anastasiia V. Shabalina ${ }^{3}$ \\ 1 Department of Chemical Engineering, School of Earth Sciences and Engineering, National Research Tomsk \\ Polytechnic University, Lenin Avenue 30, 634050 Tomsk, Russia; ms.engr9@gmail.com (M.S.); \\ elena-dorozhko@yandex.ru (E.V.D.); eikor@tpu.ru (E.I.K.) \\ 2 UNESCO Laboratory of Environmental Electrochemistry, Department of Analytical Chemistry, Faculty of \\ Science, Charles University in Prague, Albertov 6, CZ-12843 Prague 2, Czech Republic; vyskocil@natur.cuni.cz \\ 3 Laboratory of Physical and Chemical Method of Analysis, National Research Tomsk State University, Lenin \\ Avenue 36, 634050 Tomsk, Russia; shabalinaav@gmail.com \\ * Correspondence: barek@natur.cuni.cz; Tel.: +420-221-951-224
}

check for updates

Citation: Saqib, M.; Dorozhko, E.V.; Barek, J.; Vyskocil, V.; Korotkova, E.I.; Shabalina, A.V. A Laser Reduced Graphene Oxide Grid Electrode for the Voltammetric Determination of Carbaryl. Molecules 2021, 26, 5050. https://doi.org/10.3390/molecules 26165050

Received: 7 July 2021

Accepted: 2 August 2021

Published: 20 August 2021

Publisher's Note: MDPI stays neutral with regard to jurisdictional claims in published maps and institutional affiliations.

Copyright: (c) 2021 by the authors. Licensee MDPI, Basel, Switzerland. This article is an open access article distributed under the terms and conditions of the Creative Commons Attribution (CC BY) license (https:// creativecommons.org/licenses/by/ $4.0 /)$.

\begin{abstract}
Laser-reduced graphene oxide (LRGO) on a polyethylene terephthalate (PET) substrate was prepared in one step to obtain the LRGO grid electrode for sensitive carbaryl determination. The grid form results in a grid distribution of different electrochemically active zones affecting the electroactive substance diffusion towards the electrode surface and increasing the electrochemical sensitivity for carbaryl determination. Carbaryl is electrochemically irreversibly oxidized at the secondary amine moiety of the molecule with the loss of one proton and one electron in the $\mathrm{pH}$ range from 5 to 7 by linear scan voltammetry (LSV) on the LRGO grid electrode with a scan rate of $300 \mathrm{mV} / \mathrm{s}$. Some interference of the juice matrix molecules does not significantly affect the LSV oxidation current of carbaryl on the LRGO grid electrode after adsorptive accumulation without applied potential. The LRGO grid electrode can be used for LSV determination of carbaryl in fruit juices in the concentration range from 0.25 to $128 \mathrm{mg} / \mathrm{L}$ with LOD of $0.1 \mathrm{mg} / \mathrm{L}$. The fabrication of the LRGO grid electrode opens up possibilities for further inexpensive monitoring of carbaryl in other fruit juices and fruits.
\end{abstract}

Keywords: laser reduced graphene oxide; grid electrode; graphene oxide; linear sweep voltammetry; carbaryl; pesticides

\section{Introduction}

Pesticides have greatly enhanced crop productivity. However, their widespread application has resulted in the undesirable contamination of the environment. In particular, pesticide contamination of water has become a serious environmental problem in the last few decades. Indeed, the long-term impacts of contaminated water on human health as well as other species are of great concern [1].

Carbaryl (Figure 1) is a carbamate insecticide applied to crops which has been classified as a possible carcinogen by the United States Environmental Protection Agency [2]. Carbaryl can harm the human immune system, central nervous system, and endocrine system. According to the United States National Water-Quality Assessment Program, carbaryl is one of the most commonly identified insecticides in water [3] and thus it can negatively affect aquatic organisms as well as humans [2]. In Russia, the carbaryl levels are allowed in the range of $0.002-2.0 \mathrm{mg} / \mathrm{kg}$ in milk products, maize, and grains. According to European regulations, the maximum residue level (MRL) for carbaryl is $10 \mu \mathrm{g} / \mathrm{kg}$ for apples, potatoes, and tomatoes, and $50 \mu \mathrm{g} / \mathrm{kg}$ for strawberries [4]. 


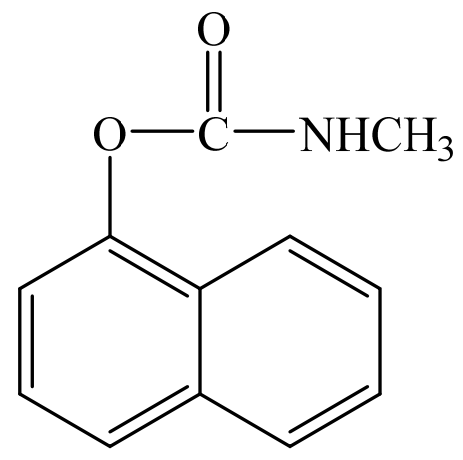

Figure 1. Structural formula of carbaryl.

There are several methods for the determination of carbaryl such as differential pulse voltammetry (DPV) [5,6], linear sweep anodic stripping voltammetry [7], colorimetry [8], chronoamperometry [9], fluorimetry [10], high-performance liquid chromatography [11], and gas chromatography [12]. Chromatographic methods are usually time-consuming, expensive, and somewhat complicated. Therefore, electrochemical techniques attract interest because they are simple, cost-effective, and reasonably sensitive and selective [13]. Moreover, their performance can be substantially improved by working electrode modification with various nanoparticles and carbon nanostructures [14] (Table 1).

Table 1. Electrochemical methods for the determination of carbaryl in various matrices.

\begin{tabular}{|c|c|c|c|c|c|}
\hline Method & Electrode & $\begin{array}{c}\text { Linear } \\
\text { Range }(\mu \mathrm{M})\end{array}$ & $\begin{array}{l}\text { LOD } \\
(\mu \mathrm{M})\end{array}$ & Matrix & Reference \\
\hline DPV & $\mathrm{CoO} / \mathrm{rGO} / \mathrm{GCE}$ & $0.50-200$ & 0.037 & Fruits & [5] \\
\hline SWV & GC/MWCNT/CoPc & $0.30-6.61$ & 0.005 & River water & [15] \\
\hline DPV & $\mathrm{rGO} / \mathrm{Cu} / \mathrm{CuO}-\mathrm{Ag} / \mathrm{GCE}$ & $0.05-20.0$ & 0.005 & Fruits & [16] \\
\hline $\mathrm{CV}$ & Graphene-modified boron-doped diamond electrode & $1-6$ & 0.07 & Fruits & [17] \\
\hline SWV & Graphene oxide-ionic liquid/GCE & $0.10-12.0$ & 0.02 & Fruits & [14] \\
\hline AdSV & GCE-CoO/reduced graphene oxide & $0.5-200$ & 0.021 & $\begin{array}{l}\text { Fruits and } \\
\text { vegetable }\end{array}$ & [18] \\
\hline DPV & GCE-graphene oxide/ionic liquid & $0.1-12.0$ & 0.02 & Fruits & [19] \\
\hline $\mathrm{CV}$ & GCE modified by MIP decorated by rGO and Au nanoparticles & $1-6$ & 0.07 & Apple juice & [20] \\
\hline $\mathrm{CV}$ & SPE-carbon black nanoparticle & $0.1-100$ & 0.048 & Wheat & [21] \\
\hline
\end{tabular}

DPV: differential pulse voltammetry; SWV: square wave voltammetry; CV: cyclic voltammetry; AdSV: adsorptive stripping voltammetry; rGO: reduced graphene oxide; GCE: glassy carbon electrode; GC/MWCNT/CoPc: multi-walled carbon nanotube/cobalt phthalocyanine modified electrode.

The key to the successful application of electrochemical methods for pesticide detection is an adequate electrode material with low cost, a broad potential window, high signal-to-noise ratio, and good electrical conductivity. Graphene, a two-dimensional carbon material, has attracted increasing attention during recent years because of its excellent properties [22]. Reduced graphene oxide (rGO) is another promising material for electronic devices and sensors for pesticides detection [23]. Carbon nanomaterials are generally used to improve the working electrodes electroanalytical performance [24]. The large surface area combined with graphene's excellent electrochemical properties increases the electron transfer rate and detection sensitivity [25].

Unfortunately, in most cases, expensive carbon materials decorated with $\mathrm{Co}, \mathrm{Ag}$, and Au nanoparticles produced by laborious methods are used for the electrochemical determination of carbaryl in different objects. The situation can be improved by applying laser-reduced graphene oxide to the PET substrate to obtain an LRGO (laser reduced graphene oxide) grid electrode for inexpensive determination of carbaryl. LRGO on PET substrate is recognized as one of the most versatile electrode materials used in electroanalysis [26]. The grid form results in a grid distribution of different electrochemically active zones, which affects the electroactive substance diffusion front to the electrode surface, 
thus increasing the electrochemical sensitivity. In this paper, the newly prepared LRGO grid electrode was successfully applied for the determination of carbaryl in fresh juices. The sensitivity of this determination was greatly increased by adsorptive accumulation of carbaryl without applied potential (open circuit potential, OCP) at the LRGO grid electrode.

\section{Results and Discussion}

\subsection{Characterization of the Laser Reduced Graphene Oxide Electrode}

The morphological properties of the prepared LRGO electrodes were examined by SEM. Figure 2A shows the SEM images of graphene oxide electrode before laser treatment, which has a smooth surface structure similar to silk. However, reduced graphene oxide electrode prepared by laser treatment shown in Figure 2B displays the expected leaflike surfaces with wrinkles and folded precincts suitable for the adsorption of carbaryl molecules. Figure $2 \mathrm{C}$ shows the LRGO grid electrode on which electroactive micro-sized zones of the LRGO grid and PET zones alternate. These observations can be explained by the presence of $\mathrm{sp}^{3}$ carbon atoms and the formation of oxygen-containing functional groups in the basal planes and by various GO structural defects [27]. According to the SEM images in Figure 2, the number of layers reduces and amorphization occurs during graphite oxidation. The degree of aggregation of the LRGO grid electrode is higher than that of the GO electrode, the rGO electrode, and the LRGO planar electrode. The reduction of oxygen-containing functional groups placed in the basal plane of the $\mathrm{sp}^{2}$ carbon permits the lamellas of the LRGO sheets to be held together via weak van der Waal forces. Consequently, LRGO sheets are highly aggregated with crumpled features, as shown in their SEM images in Figure 2B [28].
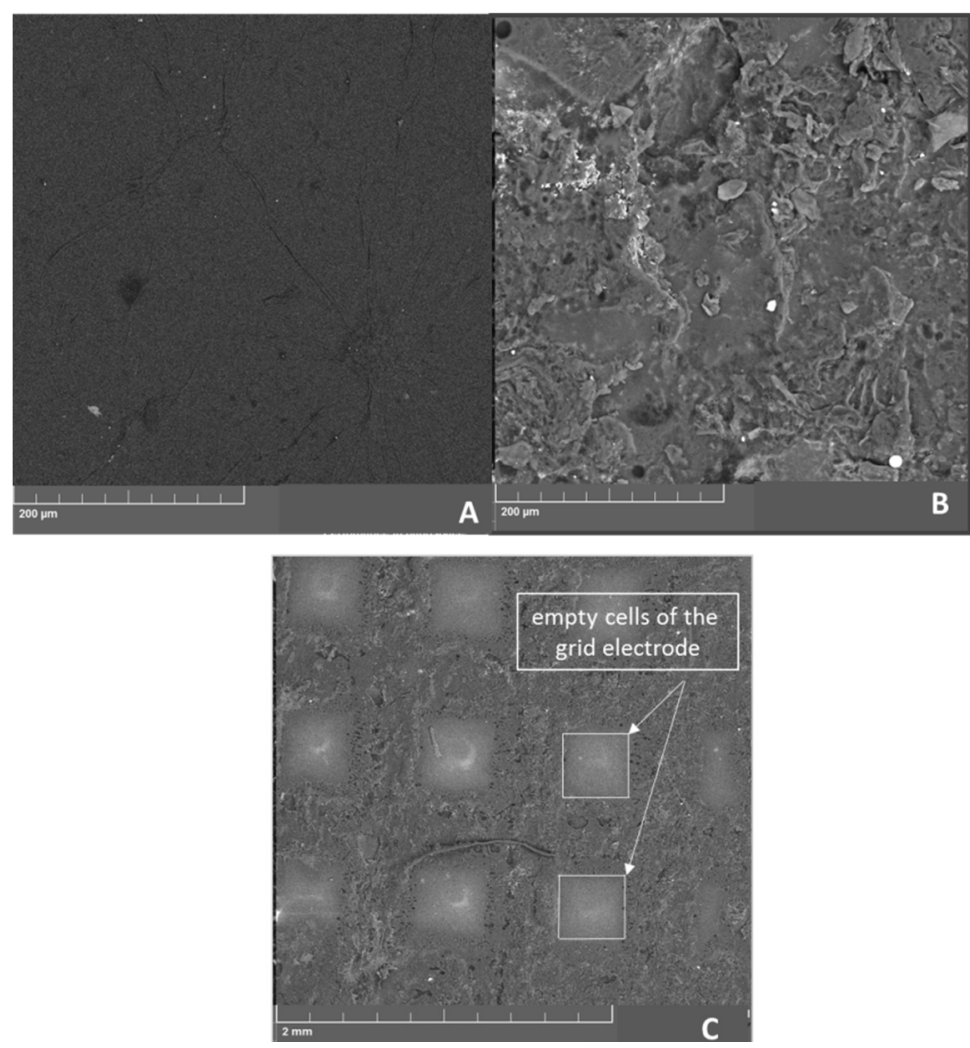

Figure 2. SEM micrographs of (A) graphene oxide electrode (B) LRGO grid electrode with high resolution (C) LRGO gird electrode with low resolution.

The electrochemical behavior of the LRGO planar and grid electrodes was investigated by $\mathrm{CV}$ using $0.01 \mathrm{~mol} / \mathrm{L}\left[\mathrm{Fe}(\mathrm{CN})_{6}\right]^{3-/ 4-}$ in $0.1 \mathrm{M} \mathrm{KCl}$ as a probe at $100 \mathrm{mV} / \mathrm{s}$ (Figure 3). 


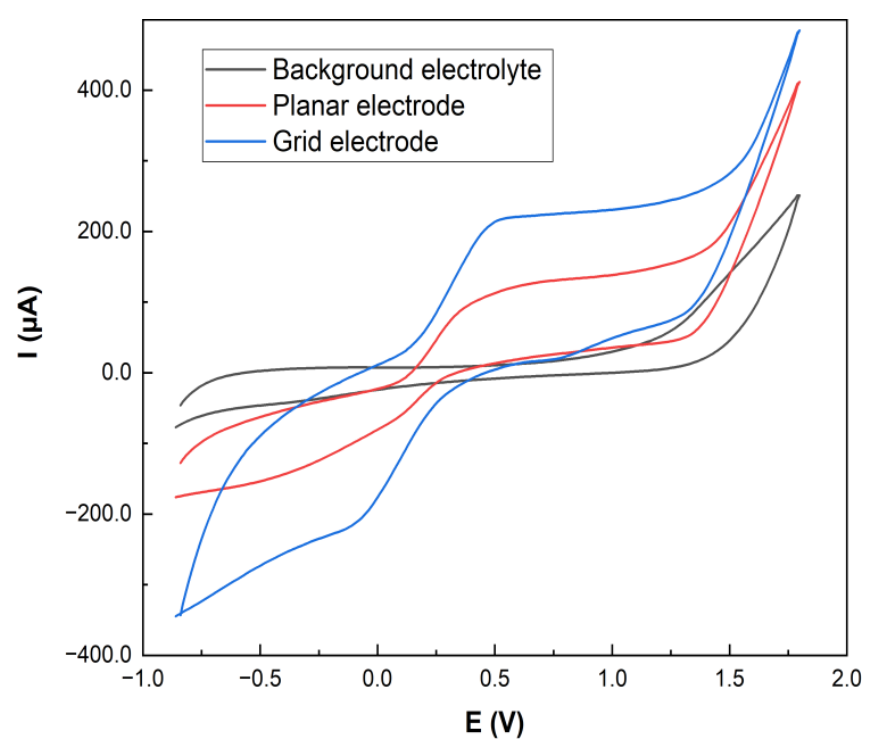

Figure 3. Cyclic voltammograms at $100 \mathrm{mV} / \mathrm{s}$ of $0.01 \mathrm{~mol} / \mathrm{L}\left[\mathrm{Fe}(\mathrm{CN})_{6}\right]^{3-/ 4-}$ solution in $0.1 \mathrm{~mol} / \mathrm{L} \mathrm{KCl}$ at planar and grid LRGO electrodes.

The grid distribution of the zones of different electrochemical activity affects the electroactive substance diffusion front to the electrode surface as well as the electrochemical sensitivity [29]. Figure 3 shows that higher redox currents of $\left[\mathrm{Fe}(\mathrm{CN})_{6}\right]^{3-/ 4-}$ are observed on the LRGO grid electrode than on the LRGO planar electrode. Figure 4 shows the dependences of the redox currents $\left[\mathrm{Fe}(\mathrm{CN})_{6}\right]^{3-/ 4-}$ on the square root of scan rate on the LRGO planar (a) and LRGO grid (b) electrodes.

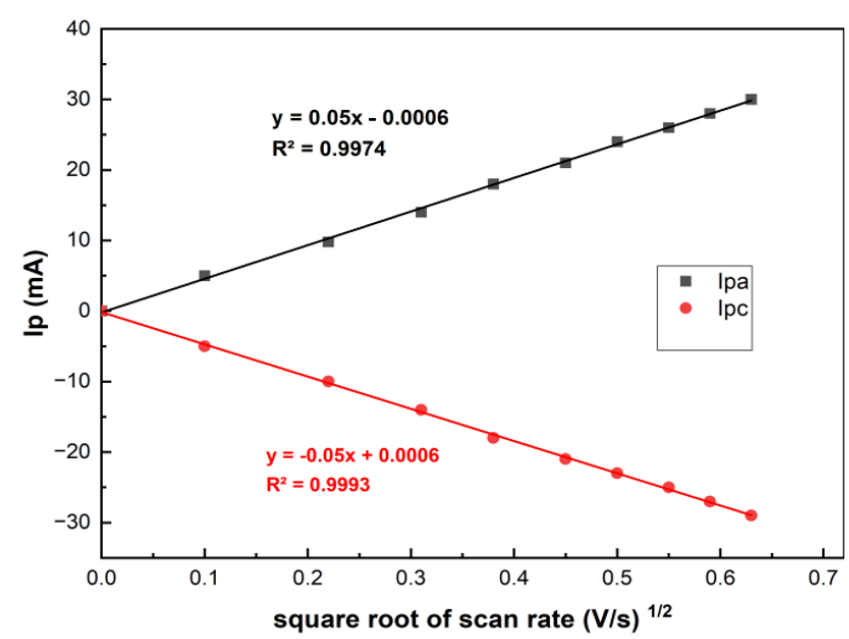

(a)

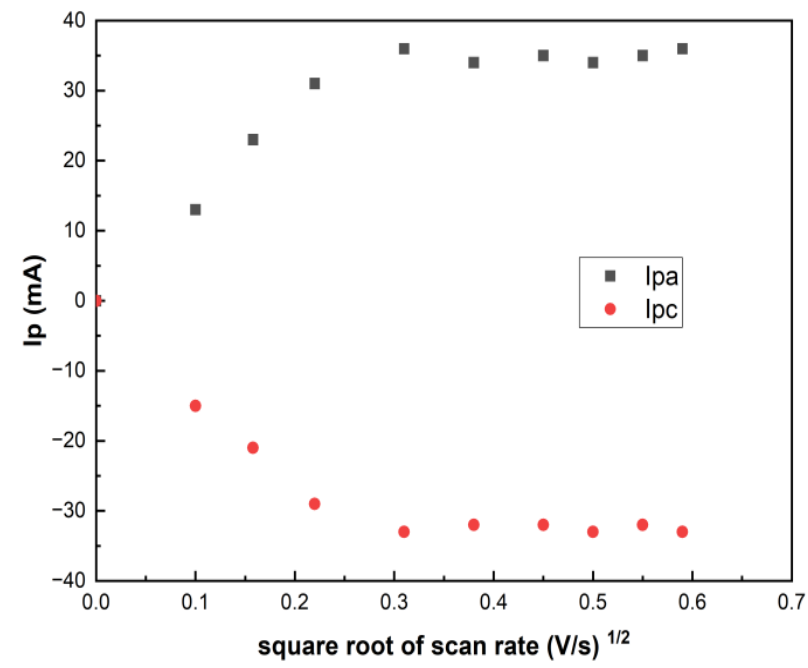

(b)

Figure 4. The dependences of the $\mathrm{CV}$ redox peak currents of $0.01 \mathrm{~mol} / \mathrm{L}\left[\mathrm{Fe}(\mathrm{CN})_{6}\right]^{3-/ 4-}$ in $0.1 \mathrm{~mol} / \mathrm{L} \mathrm{KCI}$ on the square root of scan rate on LRGO planar (a) and LRGO grid (b) electrodes.

There is a linear dependence of $\left[\mathrm{Fe}(\mathrm{CN})_{6}\right]^{3-/ 4-}$ redox peak currents on the square root of the scan rate for the LRGO planar electrode, which is typical for diffusion-controlled processes (Figure 4a). For the LRGO grid electrode, the dependence of the redox peak currents on the square root of the scan rate is more complex (Figure $4 \mathrm{~b}$ ) which indicates more complex behavior. This can be explained by the fact that the LRGO planar electrode with planar (linear) diffusion differs from the LRGO grid electrode which is a set of LRGO microelectrodes, each of which enables both radial and linear diffusion. This leads to an 
increase in redox peak currents of $\left[\mathrm{Fe}(\mathrm{CN})_{6}\right]^{3-/ 4-}$ at the $\mathrm{LRGO}$ grid electrode and the same can be envisaged for other analytes.

\subsection{Electrochemical Behavior of Carbaryl on the Laser Reduced Graphene Oxide Grid Electrode}

Cyclic voltammograms of carbaryl in PBS (pH 6.86) on LRGO plane (curve 3) and LRGO grid (curve 4) electrode are shown in Figure $5 a$.

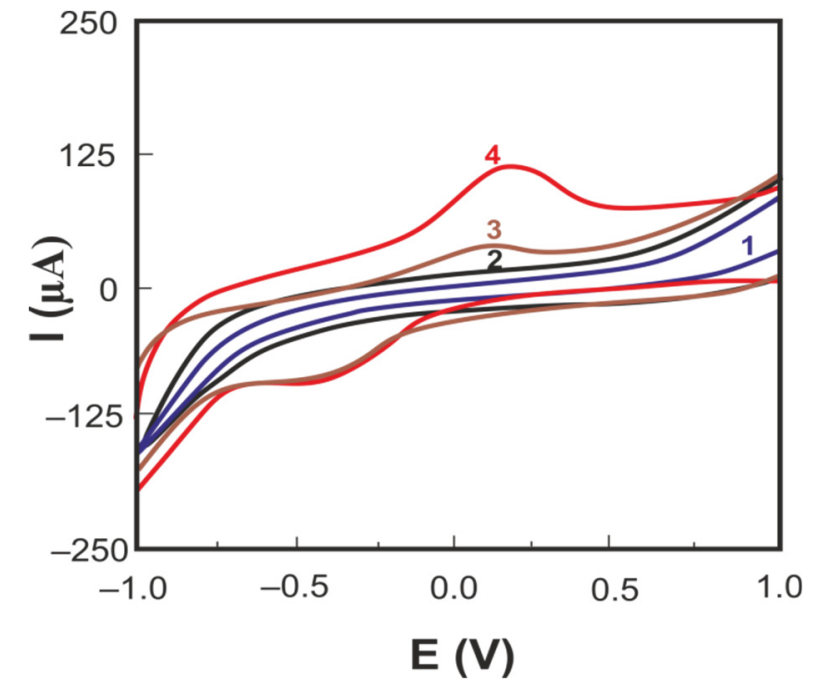

(a)

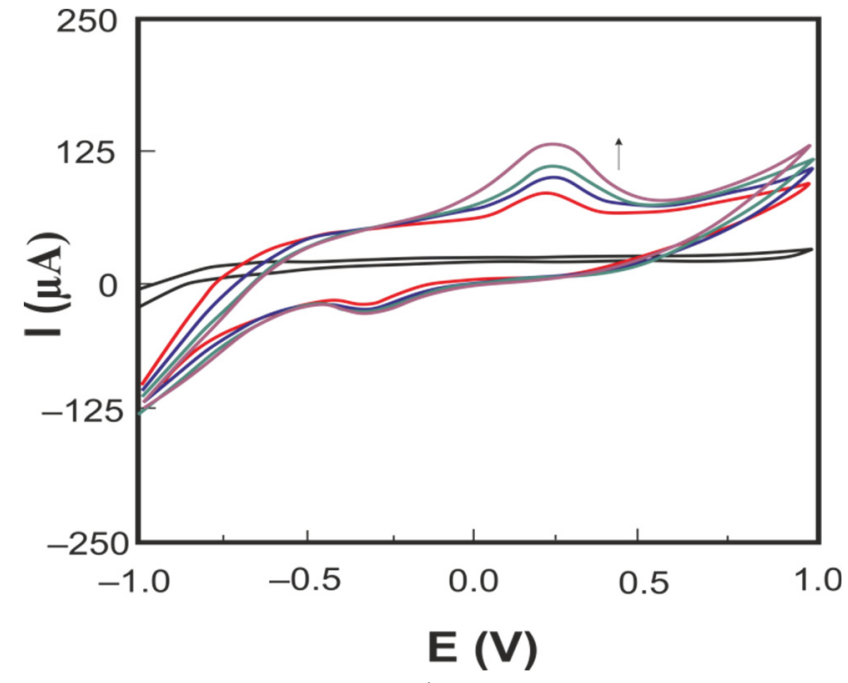

(b)

Figure 5. (a) Cyclic voltammograms of carbaryl (30 mg/L in $96 \%$ ethanol and deionized water (1:1)) on the LRGO plane electrode (curve 3) in the background electrolyte PBS (pH 6.86) (curve 1) and on the LRGO grid electrode (curve 4) in the background electrolyte PBS ( $\mathrm{pH}$ 6.86) (curve 2); (b) cyclic voltammograms of carbaryl (30 mg/L in $96 \%$ ethanol and deionized water (1:1)) on the LRGO grid electrode in background electrolyte PBS (pH 6.86) (black curve) at different scan rates $(0.2 ; 0.3 ; 0.4 ; 0.5 \mathrm{~V} / \mathrm{s})$.

There are well-developed CV oxidation peaks of carbaryl both on the LRGO plane electrode $\left(\mathrm{I}_{\mathrm{pa}}=25 \mu \mathrm{A}\right.$ and $\left.\mathrm{E}_{\mathrm{pa}}=0.125 \mathrm{~V}\right)$ and on the LRGO grid electrode $\left(\mathrm{I}_{\mathrm{pa}}=62 \mu \mathrm{A}\right.$, $\left.\mathrm{E}_{\mathrm{pa}}=0.175 \mathrm{~V}\right)$ (Figure $\left.5 \mathrm{a}\right)$. Lower and more negatively positioned $(\Delta \mathrm{Ep} \sim 0.65 \mathrm{~V})$ cathodic peaks nearly independent of the carbaryl concentration confirm irreversible behavior of carbaryl at both electrodes. The anodic CV peak of carbaryl on the LRGO grid electrode is 2.5 times higher than that on the LRGO plane electrode. Therefore, all further studies were carried out using the LRGO grid electrode, since this electrode is a more sensitive sensor for the determination of carbaryl. Figure $5 b$ shows the $\mathrm{CV}$ of carbaryl on the LRGO grid electrode at different scan rates. The linear dependence of the anodic peak current on the scan rate (Figure 6a) indicates that the electrode process of carbaryl oxidation is controlled by adsorption. To increase the height of registered carbaryl oxidation signal, the LSV mode was used in further experiments.

The effect of $\mathrm{pH}$ on the LSV of carbaryl was evaluated from $\mathrm{pH} 3.0$ to $\mathrm{pH} 10.0$ in BR buffer (see Figure 6b). 


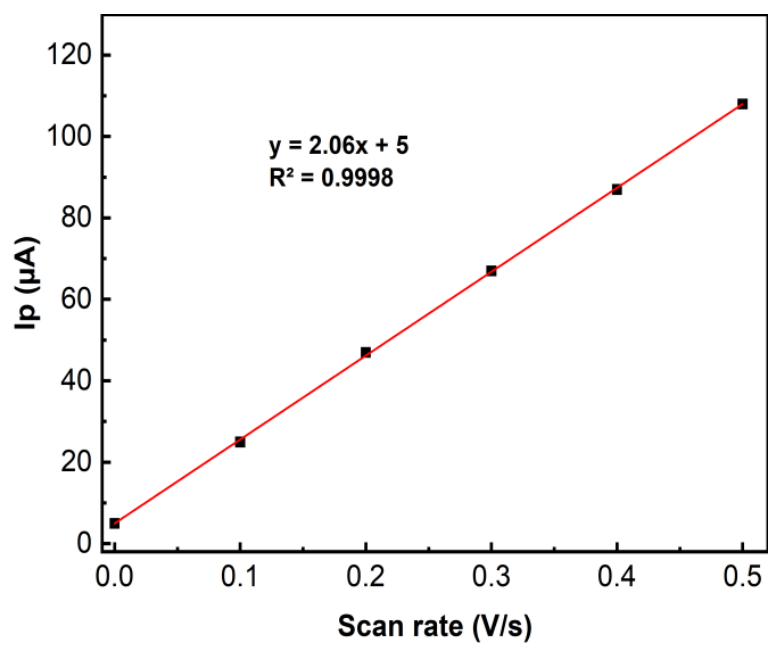

(a)

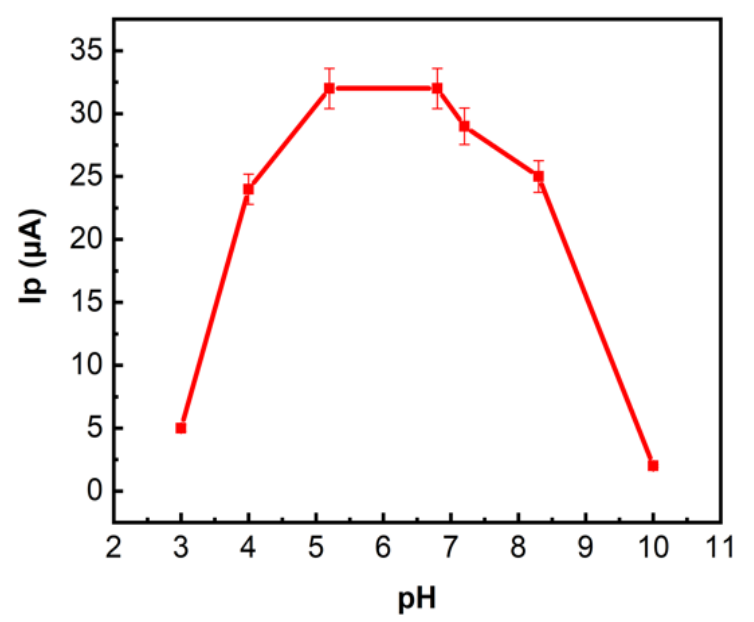

(b)

Figure 6. (a) The dependence of the carbaryl (15 mg/L in $96 \%$ ethanol and deionized water (1:1)) CV anodic peak currents in BR buffer solution $(7.00 \mathrm{pH})$ on the scan rate $(0.1 \mathrm{~V} / \mathrm{s}$ to $0.5 \mathrm{~V} / \mathrm{s})$; (b) Influence of $\mathrm{pH}$ on the LSV anodic peak current of carbaryl (15 mg/L in 96\% ethanol and deionized water (1:1)) on the LRGO grid electrode in BR buffers of different $\mathrm{pH}$ values; scan rate of $300 \mathrm{mV} / \mathrm{s} . \mathrm{n}=3$

Figure $6 \mathrm{~b}$ shows that the maximum LSV peak current is obtained at $\mathrm{pH} 5-7$. Carbaryl is electrochemically oxidized at the secondary amine moiety of the molecule with the loss of one proton and one electron [15] (see Equation (1))<smiles>C[NH+]([IH])C(=O)Oc1cccc2ccccc12</smiles>

At low $\mathrm{pH}$, the nitrogen of the carbaryl molecule is protonated, which makes the loss of an electron more difficult, and at a $\mathrm{pH}$ above 8 it is hydrolyzed to naphthol analogue, which leads to a sharp decrease in the carbaryl oxidation current [30]. In further studies, PBS ( $\mathrm{pH}$ 6.86) was used to determine carbaryl.

\subsection{The Effect of Adsorptive Accumulation Time on the Carbaryl Response on LRGO Grid Electrode}

It is known that rGO-based materials are promising for the adsorption of organophosphorus insecticides from aqueous solutions at open circuit potential [31]. This can be the basis of their determination via adsorptive accumulation without applied potential (OCP). This work is the first to report the possibility of using an LRGO grid electrode for LSV of carbaryl in a water-ethanol mixed solution after adsorptive accumulation without applied potential.

To prove that the LRGO grid electrode can be used for the adsorptive accumulation of carbaryl, UV-vis spectra of the carbaryl solution before and after adsorption are shown in Figure 7a. The freshly prepared carbaryl $(15 \mathrm{mg} / \mathrm{L})$ showed a maximum absorbance at $275 \mathrm{~nm}$, which is the characteristic absorbance peak of carbaryl [32]. After the LRGO grid electrode was immersed into the carbaryl solution for $10 \mathrm{~min}$ (maximum adsorption time), the absorbance decreased, indicating the decreased amount of carbaryl in the solution due to adsorption of some carbaryl onto the LRGO grid electrode surface. The measurement of the absorbance of the carbaryl solution before and after adsorptive accumulation on the LRGO grid electrode was carried out by transferring a drop of the solution from the electrode surface to the micro cuvettes (volume of $4 \mu \mathrm{L}$ ) of the spectrophotometer. It should 
be noted that rGO particles are firmly bounded on LRGO grid electrode and thus do not diffuse into carbaryl solution and do not interfere with carbaryl spectrophotometric monitoring as confirmed by control experiments.

To study the effect of the adsorptive accumulation time without applied potential (OCP) on the LSV oxidation peak height of carbaryl, a $200 \mu \mathrm{L}$ carbaryl solution (15 mg/L) was dropped onto the LRGO grid electrode surface and kept for various times from 1 to 15 min without applied potential. Before recording the oxidation current by LSV from -0.75 to $1.5 \mathrm{~V}$ in PBS ( $\mathrm{pH}$ 6.86), the electrodes were rinsed with distilled water. The dependence of the peak current of carbaryl oxidation on the time of adsorptive accumulation of carbaryl without applied potential on the LRGO grid electrode is shown in Figure $7 \mathrm{~b}$. The optimum time for the adsorptive accumulation of carbaryl on the LRGO grid electrode is $10 \mathrm{~min}$. The $\mathrm{pH}$ does not influence the accumulation of carbaryl on the LRGO grid electrode.

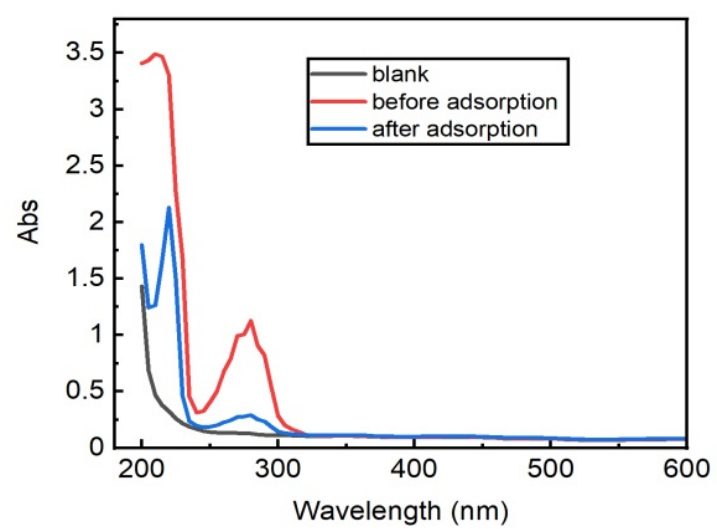

(a)

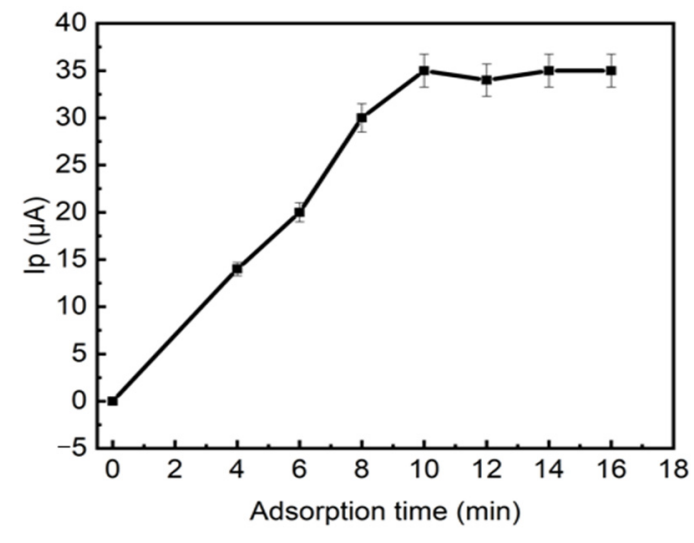

(b)

Figure 7. (a) UV-vis spectra of carbaryl solution (16 mg/L) in mixture of $96 \%$ ethanol and deionized water (1:1) before and after adsorptive accumulation on the LRGO grid electrode. Blank-96\% ethanol and deionized water (1:1), measured in 4 $\mu \mathrm{L}$ cuvettes. (b) Influence of adsorptive accumulation time on the LSV anodic peak current of carbaryl (16 mg/L) on the LRGO grid electrode.

The LRGO grid electrode has better detection performance than the planar electrode because of its higher conductivity and higher signal/noise ratio. The alternation of empty cells with protrusions, ribs and vertices of the $\mathrm{rGO}$ at the grid electrode after laser treatment allows an increase in the site number with high local surface energy, promoting the adsorption of carbaryl on the grid electrode in comparison with planar electrode.

\subsection{Analytical Performance}

Figure 8a shows the anodic LSVs of carbaryl after its adsorptive accumulation for 10 min on the surface of the LRGO grid electrode. The LSV peak heights are proportional to the carbaryl concentration in the range from 0.25 to $128.0 \mathrm{mg} / \mathrm{L}$ (Figure 8b). A limit of detection (LOD) of $0.1 \mathrm{mg} / \mathrm{L}$ was obtained based on $3 \mathrm{~S} / \mathrm{N}$. 


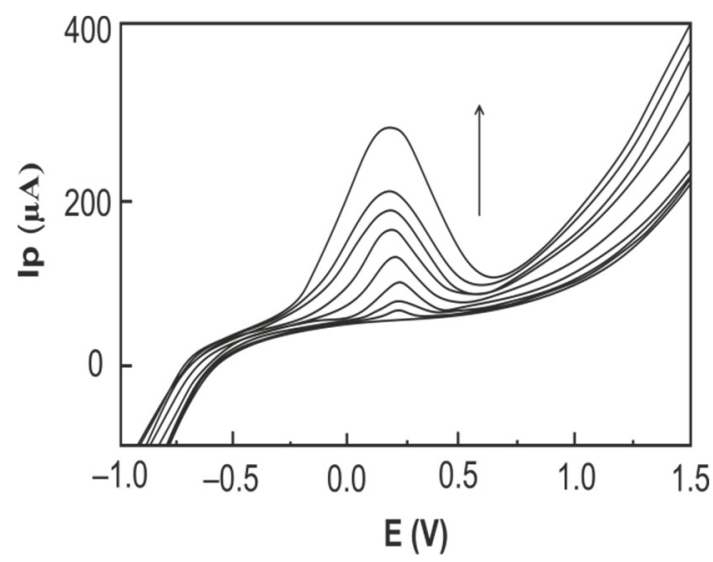

(a)

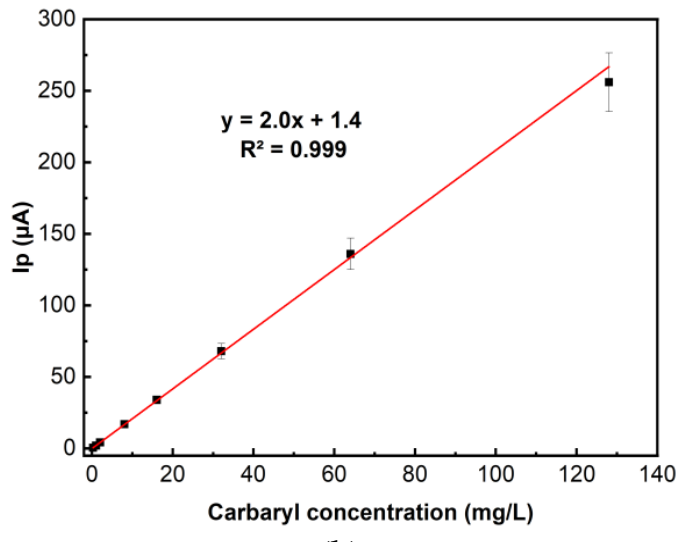

(b)

Figure 8. (a) Anodic LSVs of carbaryl (increasing concentration $0 ; 0.25 ; 1.0 ; 2.0 ; 8.0 ; 16.0 ; 32.0 ; 64.0 ; 128.0 \mathrm{mg} / \mathrm{L}$ in $96 \%$ ethanol and deionized water (1:1)) at LRGO grid electrode in PBS (pH 6.86) at $300 \mathrm{mV} / \mathrm{s}$. The adsorptive accumulation time of carbaryl from the solution was $10 \mathrm{~min}$. (b) Calibration dependence of the LSV anodic peak height on carbaryl concentration.

To investigate the LRGO grid electrodes for the determination of carbaryl in fruit juices, we have explored the effects of juice matrix components on the anodic LSV peak current of carbaryl (Figure 9).

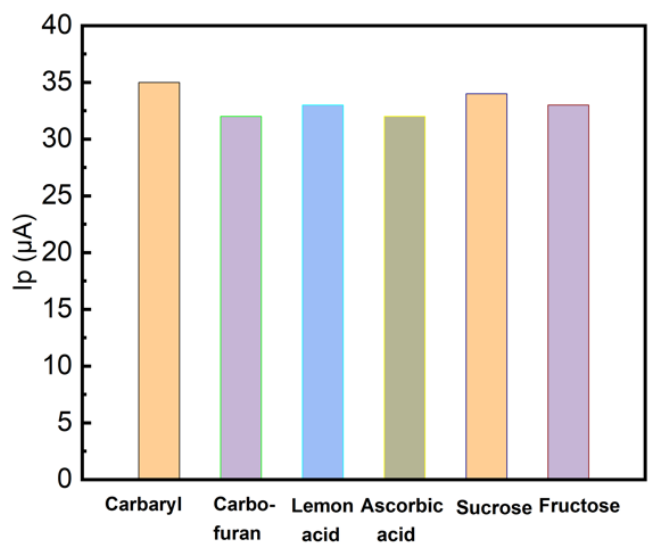

Figure 9. LSV anodic peak height of carbaryl (16 mg/L in 96\% ethanol and deionized water (1:1)) at LRGO grid electrode. Adsorptive accumulation for $10 \mathrm{~min}$ in PBS (pH 6.86) containing carbaryl in the absence and presence of 10-fold concentration of carbofuran, citric and ascorbic acids, sucrose and fructose, respectively. The scan rate $300 \mathrm{mV} / \mathrm{s}$.

The carbaryl concentration was $16 \mathrm{mg} / \mathrm{L}$ and carbofuran was chosen as a model interfering component of carbamate nature. When 10-fold amount of carbofuran, citric and ascorbic acid, sucrose and fructose were added, the results were practically unaffected (RSD $<5 \%$ ), because the direct electrochemical detection of carbaryl utilizes the electrochemical activity of the nitrogen of the naphthyl ester of $\mathrm{N}$-methylcarbamic acid. Carbofuran shows its electrochemical activity only after alkaline hydrolysis in the form of carbofuran-phenol [21] and does not significantly affect the determination of carbaryl.

To further demonstrate the practical applicability of the proposed method, a recovery test was performed by adding different amounts of carbaryl $(0.25 ; 31.25$; and $125 \mathrm{mg} / \mathrm{L})$ to freshly prepared apple and orange juices, and the results are summarized in Table 2. 
Table 2. Recovery study of carbaryl in freshly prepared apple and orange juices $(n=3)$ in PBS (pH 6.86) with adsorptive accumulation time of $10 \mathrm{~min}$ and scan rate of $300 \mathrm{mV} / \mathrm{s}$.

\begin{tabular}{ccccc}
\hline $\begin{array}{c}\text { Juice } \\
\text { Sample }\end{array}$ & Carbaryl Added (mg/L) & Carbaryl Found (mg/L) & $\begin{array}{c}\text { Recovery } \\
\mathbf{( \% )}\end{array}$ & $\begin{array}{c}\text { RSD } \\
\mathbf{( \% )}\end{array}$ \\
\hline \multirow{3}{*}{ Apple } & 0.25 & 0.26 & 104.0 & 5.4 \\
& 31.25 & 32.82 & 105.0 & 5.0 \\
& 126.00 & 123.50 & 98.0 & 4.8 \\
\hline \multirow{3}{*}{ Orange } & 0.25 & 0.23 & 92.0 & 5.2 \\
& 31.25 & 29.55 & 94.6 & 5.0 \\
& 126.00 & 124.00 & 98.4 & 4.9 \\
\hline
\end{tabular}

The proposed LRGO grid electrodes were successfully applied for the determination of carbaryl in apple and orange juices with favorable recoveries from $92.0 \%$ to $107.0 \%$. It is also recommended for the determination of carbaryl in other fruit juices and fruits. The linearity range from 0.25 to $128.0 \mathrm{mg} / \mathrm{L}$ for the electrochemical determination of carbaryl in fruits on the LRGO grid electrode is wider, and the limit of detection (LOD) of $0.1 \mathrm{mg} / \mathrm{L}$ is comparable with previous studies (Table 1). Moreover, the LRGO grid electrode can be prepared using a simple, convenient, and inexpensive process.

\section{Materials and Methods}

\subsection{Reagents}

A carbaryl standard (99\%) and ethanol were purchased from Sigma-Aldrich (Saint Louis, MO, USA). Graphene oxide (4 $\mathrm{mg} / \mathrm{mL}$ dispersion in water) was purchased from the Graphenea company (www.graphenea.com, accessed on 1 August 2021). The apples and oranges were purchased from the local market in Tomsk, Russia.

\subsection{Preparation of the Laser Reduced Graphene Oxide Electrode}

A polyethylene terephthalate (PET) sheet $5 \times 25 \mathrm{~mm}^{2}$ in size was used as a substrate for graphene oxide (GO) film deposition by the drop-casting method without further treatment to obtain a homogeneous electrode surface (see Figure 10). The drop casting dispersion volume, concentration and solvent were optimized to obtain the most effective electrodes in terms of sensitivity and reproducibility. Briefly, $100 \mu \mathrm{L}$ of GO $(2 \mathrm{mg} / \mathrm{mL})$ was deposited by drop-casting on the PET surface and dried carefully for $2 \mathrm{~h}$ at laboratory temperature $\left(22 \pm 2{ }^{\circ} \mathrm{C}\right)$. GO to rGO conversion was performed using a laser engraver with an optimal power $(600 \mathrm{~mW})$ at wavelength of $405 \mathrm{~nm}$. There are two types of engraved electrodes: either with planar or with grid geometry. The second one enhances the surface section's sensitivity to the pesticide, and thus it was used in this paper. The size of the working grid was $12.57 \mathrm{~mm}^{2}$. The distance between the electrode and the laser head was $5 \mathrm{~mm}$ to prevent burning during the reduction.

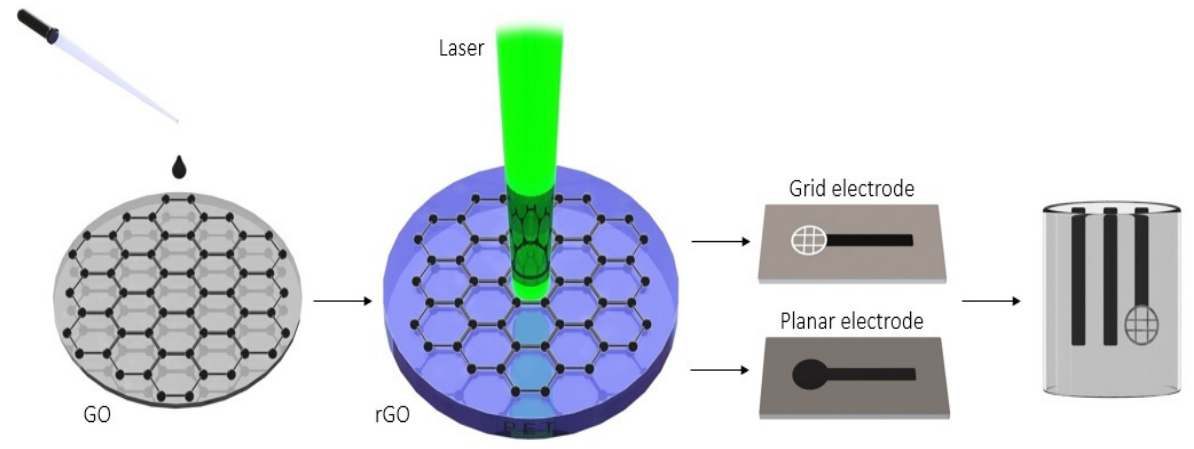

Figure 10. Schematic illustration of the fabrication of laser reduced graphene oxide electrode for the determination of carbaryl. 


\subsection{Apparatus and Measurements}

All electrochemical measurements were conducted on a portable PalmSens 4 Potentiostat analyzer (Palm Instruments BV, Houten, The Netherlands) in a three-electrode arrangement with a LRGO electrode prepared as described above as a working electrode, $\mathrm{Ag} / \mathrm{AgCl}(1 \mathrm{~mol} / \mathrm{L} \mathrm{KCl})$ as a reference electrode, and a platinum wire as a counter electrode. The structure and morphology of the LRGO electrodes (planar or grid) were investigated by high-resolution scanning electron microscopy (SEM) (Vega 3H, Tescan, Brno, Czech Republic) at Tomsk State University (Tomsk, Russia).

A standard carbaryl solution was prepared by dissolving $0.0040 \mathrm{~g}$ in $1 \mathrm{~mL}$ of a mixture of $96 \%$ ethanol and deionized water (1:1).

Both cyclic voltammetry (CV) and linear scan voltammetry (LSV) were employed for carbaryl detection in the potential range from -1.0 to $1.6 \mathrm{~V}$ in $0.1 \mathrm{~mol} / \mathrm{L}$ phosphate buffer solution (PBS) ( $\mathrm{pH}$ 6.86). The voltammograms were recorded at a potential scan rate of $300 \mathrm{mV} / \mathrm{s}$ unless stated otherwise.

A $0.1 \mathrm{~mol} / \mathrm{L}$ Britton-Robinson (BR) buffer solution was prepared in the usual way from phosphoric, glacial, acetic, and boric acid and from $1 \mathrm{~mol} / \mathrm{L} \mathrm{NaOH}$.

Apples and oranges were grated to obtain the juice. Then, $250 \mu \mathrm{L}$ of apple juice were mixed with the $250 \mu \mathrm{L}$ of carbaryl standard solution at requested concentrations for further experiments. Orange juice samples were prepared by means of the same procedure. Then, $100 \mu \mathrm{L}$ of the prepared spiked sample of juice with standard solution of carbaryl $(0.25$; $31.25 ; 126.00 \mathrm{mg} / \mathrm{L}$ ) were deposited on the electrode surface for $10 \mathrm{~min}$ using the drop casting method at laboratory conditions.

The electrode was then rinsed three times with PBS, placed into the electrochemical cell containing $8 \mathrm{~mL}$ of PBS ( $\mathrm{pH}$ 6.86) and the carbaryl oxidation signal was recorded by LSV. The limit of detection (LOD) was calculated as $3 \mathrm{~s} / \mathrm{b}$ (where $\mathrm{s}$ is the standard deviation of blank and $\mathrm{b}$ is the slope of the straight section of the calibration curve) $(\mathrm{S} / \mathrm{N}=3)$.

\section{Conclusions}

The laser-reduced graphene oxide on a PET substrate was prepared using a simple, convenient, and inexpensive technique to obtain a laser reduced graphene oxide grid electrode for sensitive carbaryl determination. The thus prepared LRGO grid electrode was used for LSV determination of carbaryl which is electrochemically irreversibly oxidized at the secondary amine moiety of the molecule with the loss of one proton and one electron in the $\mathrm{pH}$ range from 5 to 7 . Juice matrix components did not significantly affect the LSV oxidation current of carbaryl after its adsorptive accumulation without applied potential for $10 \mathrm{~min}$. The LRGO grid electrode was used for the detection of carbaryl in fruit juices in the concentration range from 0.25 to $128 \mathrm{mg} / \mathrm{L}$ with LOD of $0.1 \mathrm{mg} / \mathrm{L}$ after its adsorptive accumulation. The anodic LSV peak height of carbaryl on the LRGO grid electrode was proportional to the carbaryl concentration. It was verified that the LRGO grid electrode can be used for direct determination of carbaryl in apple and orange juices as well as other fruit juices and fruits.

Author Contributions: Conceptualization, E.V.D., E.I.K. and M.S.; methodology, E.V.D., M.S., E.I.K., J.B., V.V. and A.V.S.; software, M.S., E.V.D. and A.V.S.; validation, M.S., E.V.D., J.B., E.I.K., V.V. and A.V.S.; formal analysis, E.V.D., M.S., E.I.K., J.B., V.V. and A.V.S.; investigation, M.S., E.V.D., V.V. and A.V.S.; resources, E.I.K. and J.B.; data curation, M.S., E.V.D. and A.V.S.; writing—original draft preparation, M.S., E.V.D., J.B. and E.I.K.; writing-review and editing, E.V.D., M.S., J.B., E.I.K., V.V. and A.V.S.; visualization, E.V.D., M.S., E.I.K., J.B., V.V. and A.V.S.; supervision, E.I.K. and J.B.; project administration, E.I.K. and J.B.; funding acquisition, E.I.K. and J.B. All authors have read and agreed to the published version of the manuscript.

Funding: This research was funded by State Program "Science" of the Russian Federation No. 4.5752.2017 and RFBR 19-5326001, by Tomsk Polytechnic University within the framework of the Tomsk Polytechnic University Competitiveness Enhancement Program grant and by the Grant Agency of the Czech Republic (Project No. 20-01417J). 
Institutional Review Board Statement: Not applicable.

Informed Consent Statement: Not applicable.

Data Availability Statement: All relevant data generated during the study are included in this article.

Acknowledgments: The authors thank for financial support of the State Program "Science" of the Russian Federation No. 4.5752.2017 and RFBR 19-5326001. The research was carried out at the Tomsk Polytechnic University within the framework of the Tomsk Polytechnic University Competitiveness Enhancement Program grant. JB thanks for financial support of the Grant Agency of the Czech Republic (Project No. 20-01417J).

Conflicts of Interest: The authors declare no conflict of interest.

Sample Availability: The tested samples are available from the authors.

\section{References}

1. Derbalah, A.; Ismail, A.; Shaheen, S. On the presence of organophosphorus pesticides in drainage water and its remediation technologies. Environ. Eng. Landsc. Manag. 2016, 15, 1777-1787. [CrossRef]

2. Bazrafshan, A.A.; Ghaedi, M.; Rafiee, Z.; Hajati, S.; Ostovan, A. Nano-sized molecularly imprinted polymer for selective ultrasound-assisted microextraction of pesticide Carbaryl from water samples: Spectrophotometric determination. J. Colloid Interface Sci. 2017, 498, 313-322. [CrossRef]

3. Chattoraj, S.; Mondal, N.K.; Das, B.; Roy, P.; Sadhukhan, B. Carbaryl removal from aqueous solution by Lemna major biomass using response surface methodology and artificial neural network. J. Environ. Chem. Eng. 2014, 2, 1920-1928. [CrossRef]

4. EU Pesticides Database. Available online: http://ec.europa.eu/food/plant/pesticides/eu-pesticides-database/public/?event= homepage\&language $=\mathrm{EN}$ (accessed on 3 August 2021).

5. Wang, M.; Huang, J.; Wang, M.; Zhang, D.; Chen, J. Electrochemical nonenzymatic sensor based on CoO decorated reduced graphene oxide for the simultaneous determination of carbofuran and carbaryl in fruits and vegetables. Food Chem. 2014, 151, 191-197. [CrossRef] [PubMed]

6. Rahmani, T.; Bagheri, H.; Behbahani, M.; Hajian, A.; Afkhami, A. Modified 3D graphene-Au as a novel sensing layer for direct and sensitive electrochemical determination of carbaryl pesticide in fruit, vegetable, and water samples. Food Anal. Methods 2018, 11, 3005-3014. [CrossRef]

7. Dorozhko, E.V.; Gashevskay, A.S.; Korotkova, E.I.; Barek, J.; Vyskocil, V.; Eremin, S.A.; Galunin, E.V.; Saqib, M. A copper nanoparticle-based electrochemical immunosensor for carbaryl detection. Talanta 2021, 228, 122174. [CrossRef] [PubMed]

8. Rujiralai, T.; Cheewasedtham, W.; Jayeoye, T.J.; Kaewsara, S.; Plaisen, S. Hydrolyzed product mediated aggregation of L-cysteine-modified gold nanoparticles as a colorimetric probe for carbamate residues in chilis. Anal. Lett. 2020, 53, 574-588. [CrossRef]

9. Cesarino, I.; Moraes, F.C.; Lanza, M.R.V.; Machado, S.A.S. Electrochemical detection of carbamate pesticides in fruit and vegetables with a biosensor based on acetylcholinesterase immobilised on a composite of polyaniline-carbon nanotubes. Food Chem. 2012, 135, 873-879. [CrossRef]

10. Long, Z.; Shen, S.; Lu, Y.; Lan, W.; Chen, J.; Qiu, H.D. Monodisperse core-shell-structured $\mathrm{SiO}_{2} @ \mathrm{Gd}_{2} \mathrm{O}_{3}: \mathrm{Eu}^{3+} @ S i \mathrm{~S}_{2} @ \mathrm{MIP}$ nanospheres for specific identification and fluorescent determination of carbaryl in green tea. Anal Bioanal. Chem. 2019, 411, 4221-4229. [CrossRef]

11. Bilehal, D.C.; Chetti, M.B.; Deepa, G.T.; Khetagoudar, M.C. Multiresidue Pesticide analysis using QuEChERS method in vegetable samples by Ultra-Performance Liquid Chromatography. Anal. Chem. Lett. 2016, 6, 688-696. [CrossRef]

12. Cavaliere, B.; Monteleone, M.; Naccarato, A.; Sindona, G.; Tagarelli, A. A solid-phase microextraction-gas chromatographic approach combined with triple quadrupole mass spectrometry for the assay of carbamate pesticides in water samples. $J$. Chromatogr. A 2012, 1257, 149-157. [CrossRef]

13. Rousis, N.I.; Bade, R.; Bijlsma, L.; Zuccato, E.; Sancho, J.V.; Hernandez, F.; Castiglioni, S. Monitoring a large number of pesticides and transformation products in water samples from Spain and Italy. Environ. Res. 2017, 156, 31-38. [CrossRef]

14. Luo, S.; Wu, Y.; Gou, H. A voltammetric sensor based on GO-MWNTs hybrid nanomaterial-modified electrode for determination of carbendazim in soil and water samples. Ionics 2013, 19, 673-680. [CrossRef]

15. Moraes, F.C.; Mascaro, L.H.; Machado, S.A.S.; Brett, C.M.A. Direct electrochemical determination of carbaryl using a multi-walled carbon nanotube/cobalt phthalocyanine modified electrode. Talanta 2009, 79, 1406-1411. [CrossRef]

16. Hashemi, P.; Karimian, N.; Khoshsafar, H.; Arduini, F.; Mesri, M.; Afkhami, A.; Bagheri, H. Reduced graphene oxide decorated on $\mathrm{Cu} / \mathrm{CuO}-\mathrm{Ag}$ nanocomposite as a high-performance material for the construction of a non-enzymatic sensor: Application to the determination of carbaryl and fenamiphos pesticides. Mater. Sci. Eng. C 2019, 102, 764-772. [CrossRef] [PubMed]

17. Pop, A.; Manea, F.; Flueras, A.; Schoonman, J. Simultaneous Voltammetric detection of carbaryl and paraquat pesticides on graphene-modified boron-doped diamond electrode. Sensors 2017, 17, 2033. [CrossRef] [PubMed]

18. Silva, T.A.; Moraes, F.C.; Janegitz, B.C.; Fatibello-Filho, O. Electrochemical biosensors based on nanostructured carbon black: A review. J. Nanomater. 2017, 2017, 4571614. [CrossRef] 
19. Salih, F.E.; Achiou, B.; Ouammou, M.; Bennazha, J.; Ouarzane, A.; Younssi, S.A.; El Rhazi, M. Electrochemical sensor based on low silica $X$ zeolite modified carbon paste for carbaryl determination. J. Advert. Res. 2017, 8, 669-676. [CrossRef] [PubMed]

20. Tan, X.; Hu, Q.; Wu, J.; Li, X.; Li, P.; Yu, H.; Li, X.; Lei, F. Electrochemical sensor based on molecularly imprinted polymer reduced graphene oxide and gold nanoparticles modified electrode for detection of carbofuran. Sens. Actuators B Chem. 2015, 220, $216-221$. [CrossRef]

21. Della Pelle, F.; Angelini, C.; Sergi, M.; Del Carlo, M.; Pepe, A.; Compagnone, D. Nano carbon black-based screen printed sensor for carbofuran, isoprocarb, carbaryl and fenobucarb detection: Application to grain samples. Talanta 2018, 186, 389-396. [CrossRef] [PubMed]

22. Ambrosi, A.; Chua, C.K.; Bonanni, A.; Pumera, M. Electrochemistry of graphene and related materials. Chem. Rev. 2014, 114, 7150-7188. [CrossRef]

23. Yang, Y.; Asiri, A.M.; Du, D.; Lin, Y. Acetylcholinesterase biosensor based on a gold nanoparticle-polypyrrole-reduced graphene oxide nanocomposite modified electrode for the amperometric detection of organophosphorus pesticides. Analyst 2014, $139,3055$. [CrossRef]

24. Wong, A.; Silva, T.; Caetano, F.; Bergamini, M.; Marcolino-Junior, L.; Fatibello-Filho, O.; Janegitz, B. An overview of pesticide monitoring at environmental samples using carbon nanotubes-based electrochemical sensors. C 2017, 3, 8. [CrossRef]

25. Bahadır, E.B.; Sezgintürk, M.K. Applications of graphene in electrochemical sensing and biosensing. Trends Analyt. Chem. 2016, 76, 1-14. [CrossRef]

26. Rodriguez, R.D.; Shchadenko, S.; Murastov, G.; Lipovka, A.; Fatkullin, M.; Petrov, I.; Tran, T.; Khalelov, A.; Saqib, M.; Villa, N.E.; et al. Ultra-robust flexible electronics by laser-driven polymer-nanomaterials integration. Adv. Funct. Mater. 2021, 31, 2008818. [CrossRef]

27. Al-Gaashani, R.; Najjar, A.; Zakaria, Y.; Mansour, S.; Atieh, M.A. XPS and structural studies of high quality graphene oxide and reduced graphene oxide prepared by different chemical oxidation methods. Ceram. Int. 2019, 45, 14439-14448. [CrossRef]

28. Dobrota, A.S.; Pašti, I.A.; Mentus, S.V.; Skorodumova, N.V. A general view on the reactivity of the oxygen-functionalized graphene basal plane. Phys. Chem. Chem. Phys. 2016, 18, 6580-6586. [CrossRef]

29. Compton, R.G.; Banks, C.E. Understanding Voltammetry, 3rd ed.; WSPC: London, UK, 2018.

30. Garrigues, S.; de la Guardia, M.; Cassella, A.R.; de Campos, R.C.; Santelli, R.E.; Cassella, R.J. Flow injection-FTIR determination of dithiocarbamate pesticides. Analyst 2000, 125, 1829-1833. [CrossRef]

31. Maliyekkal, S.M.; Sreeprasad, T.S.; Krishnan, D.; Kouser, S.; Mishra, A.K.; Waghmare, U.V.; Pradeep, T. Graphene: A reusable substrate for unprecedented adsorption of pesticides. Small 2013, 9, 273-283. [CrossRef]

32. Zhang, C.; Cui, H.; Cai, J.; Duan, Y.; Liu, Y. Development of fluorescence sensing material based on CdSe/ZnS quantum dots and molecularly imprinted polymer for the detection of carbaryl in rice and Chinese cabbage. J. Agric. Food Chem. 2015, 63, 4966-4972. [CrossRef] 